\title{
The Artistic Features and Significance of Artistic Life Pottery in Jingdezhen City
}

\author{
Liwei Zhang and Weiwei Xu \\ Jingdezhen Ceramic University, Jingdezhen, Jiangxi 333403
}

\begin{abstract}
In today's society, as industrial mass production is widely used, Jingdezhen handmade ceramic products are favored by the mass due to its unique humanistic charm. For the creation of handmade ceramics in Jingdezhen, it is encouraged by the market, so it can continue to develop and innovate. This paper tries to start from the interpretation of works to explore the features and development trend of handmade ceramic productions in Jingdezhen in the new era.
\end{abstract}

Keywords: Life ceramics; Handmade; Characteristics; Development

\section{景德镇手工生活陶艺的艺术语言特征与意义}

\author{
张丽伟，许伟伟 \\ (景德镇陶瓷大学, 江西景德镇 333000)
}

摘要: 在工业化批量生产被广泛使用的今天, 景德镇手工制作的陶艺制品因其独具一格的人文魅力受到广大群众的喜爱。 对于景德镇手工生活陶瓷创作而言, 正是因为受到市场的鼓励, 才能够不断的发展与创新。本文将尝试从作品解读入手, 探 讨新时期景德镇手工生活陶瓷创作的特征与发展趋向。

关键词: 生活陶瓷; 手工制作; 特征; 发展

中图分类号: J024 文摘标识码: A

引言

所谓手工生活陶瓷是指以陶或瓷为媒介, 依靠手工制作的、满足日常生活使用的那部分陶瓷器血。在 生活陶瓷前冠以 “手工”一词, 主要是有意与机器生产的生活陶瓷相区别。 ${ }^{[1]}$ 正如其名称中所强调的一样, 有别于机器生产的千篇一律, 景德镇手工生活陶瓷作品因其个性化的人文表达, 受到了市场的欢迎与喜爱。 其作品中所演绎出的丰富的工艺文化也彰显了人类劳动的美好情趣与无穷智慧。因此, 分析探讨景德镇手 工生活陶瓷作品的艺术语言特征与意义, 其实就是进一步的接触和了解人类社会发展的人文风貌和历史变 迁。

\section{1. 新时期景德镇手工生活陶瓷艺术语言特征}

当下中国, 经济的高速发展催生了民众对于个性化私人定制生活物品的需求。景德镇手工生活陶瓷的 创作因其小批量生产的较低重复性以及多品种、多风格的艺术表达性顺应了社会消费发展的新需求形势, 受到了陶瓷消费市场的欢迎。从当下景德镇手工生活陶瓷创作的特征来看, 目前的手工生活陶艺作品既兼 顾了使用者的客观使用需求, 有较高的实用性, 同时也具备了创作者的艺术个性阐释, 具有比机械化生产 的陶瓷作品更高的艺术审美性, 尤其在装饰艺术上面, 较之机械化生产的作品风格也更为强烈。

对于新时期景德镇手工生活陶瓷创作的特征分析, 首先从装饰特征上来说, 体现在作品造型的异型化 和作品纹饰的多元化两个方面。以景德镇地区的手工陶瓷创作为例, 作为世界瓷都, 该地区的陶瓷创作具 有一定的典型意义。因此, 以该地区的创作作品作为解读对象, 能够发现一定的创作规律。作为新时期的 
景德镇手工陶艺作品风格体现来说, 在装饰的艺术上, 从釉色的装饰来说, 手绘风格特别盛行。其中既有 青花、古彩、粉彩和传统的装饰手法，也有运用现代化的装饰手段创新出的个性化装饰手段; 从泥坏装饰 上来说, 个性化的渗入非常突出。在表达作品的肌理效果方面, 镂空、刻花等装饰方法都会展现出一片崭 新的景象, 以期表现出不同于传统陶艺作品的个性化效果。有的甚至在制坏阶段, 就会通过泥条盘筑等传 统方法制造出异型化的器物效果, 突出作品的个人风格; 第三, 从装饰的工艺上来说, 景德镇近些年开始 流行柴烧工艺, 突出手工生活陶瓷的质朴感, 在放弃华而不实的过分装饰之余, 还能够使用户能够通过陶 瓷器物感受到生活的质朴之美，符合了当下人们追逐返璞归真的生活感受的流行趋势。

\section{2. 景德镇手工生活陶瓷创作的发展趋向分析}

手工生活陶艺其实自古有之, 最早可以追溯到彩陶文化时期。只是在工业化生产盛行之后, 景德镇手 工生活陶瓷创作由于受到产量规模大小的约束, 开始萎缩, 并由大众消费品逐渐发展成为小众日用陶瓷工 艺品。对于新时期景德镇手工生活陶瓷的发展来说, 其实从规模上它确实不如机械化的大众陶瓷生产。但 是, 不可否认的是, 随着近些年 “慢生活” 节奏的深入人心, 景德镇手工生活陶瓷创作也迈入了它的回春 之旅。越来越多的创作人才跨进景德镇手工生活陶瓷创作的行业, 并且通过个人创作, 开启了诗意手作的 生活之旅。

从纯粹的创作发展角度而言，新时期景德镇手工生活陶瓷创作体现出 “继承传统，兼容现代” 的发展 特点。一方面是在技巧上, 无论是在前期的作品坯胎制作环节，还是在中期的作品装饰环节，都能够熟练 的使用传统的陶瓷工艺技巧, 用以丰富作品的图案表现或是器形的奇特变化; 另一方面, 在创作的工艺上, 新时期的创作者们经常会使用带有专利技术的新型材料用以丰富作品的釉色发色或者是作品的强度韧性 表现, 这一点上来说, 是现代工艺对于传统行当的最有价值融合了。

\section{3. 景德镇手工生活陶瓷创作背后的文化体现与意义}

正如前文所描述的那样，景德镇手工生活陶瓷创作背后往往呈现出一定的社会价值和人文风貌。就这 个角度而言, 新时期的景德镇手工生活陶瓷其背后往往体现出较高的自然意境和纯朴的生活意义。这一点 与中国传统道家文化所崇尚的 “天人合一” 的哲学观念不谋而合。有学者说，在景德镇手工生活陶瓷作品 当中，体现出了中国古代对 “材美” 的 “审曲面势”和 “大巧若拙” 崇尚自然的思想和造物审美内涵。 这一非物质意义所表现出来的正是现代人对于日益喧器的物质社会的一种反思, 也体现了人们对于简单、 朴素的美好生活的一种向往。可以说, 景德镇手工生活陶瓷体现出来的正式艺术与生活之间的双向互动, 它完美的阐释了艺术生活化的再现与生活艺术化的演变, 现代人的审美趋向就在这一来一回的作品演绎中 得以升华。

\section{4. 结论}

手工陶瓷作为工业化陶瓷的补充, 在现代归复自然的情怀追求中表现出了强烈的吸引力。 ${ }^{[3]}$ 这种吸引 使得手工生活陶瓷能够充满生命力, 同时也尽情地展现了生活的创造力。因此, 我们可以说, 手工生活陶 瓷未来的发展趋向将会越来越好，越来越宽广。

\section{致谢}

基金项目：2014 年度教育部人文社会科学青年基金项目（14YJCZH092）、2014 年度江西省人文社会科 
学青年基金项目（JC1439）

\section{Acknowledgement}

Fund Project: 2014 Ministry of Education Humanities and Social Sciences Youth Fund Project (14YJCZH092), 2014 Jiangxi Province Humanities and Social Sciences Youth Fund Project (JC1439)

\section{参考文献}

[1]吕金泉，论手工生活陶瓷的工艺魅力 [J]，南京艺术学院学报：美术与设计版，2007 (4).

[2]汤雅丽，手作诗意的生活——浅谈陶瓷中手工[J]，艺术品鉴，2016(4).

[3]任娜、方益鸣，探析现代生活陶瓷的手工艺术 $[J]$ ，现代装饰：理论，2015(4).

\section{作者简介：}

张丽伟 (1982-) 女, 硕士，景德镇陶瓷大学讲师，研究方向为陶瓷艺术设计

许伟伟 $\left(1986^{-}\right)$女，硕士，景德镇陶瓷大学助教，研究方向为陶瓷艺术设计

\section{References}

[1] LV Jinquan, On the Artistic Charm of Handmade Ceramic [J], Journal of Nanjing Art College: Art and Design Edition, 2007 (4).

[2] Tang Yali, Handmade Poetic Life - Talking about Ceramic Handwork [J], Art Tasting, 2016 (4).

[3] Ren Na, Fang Yiming, Analysis of Ceramic Art in Modern Life [J], Modern Decoration: Theory, 2015 (4). 